\title{
Research of Floating Population and Social Security Prevention System \\ in City of Southern Xinjiang
}

\author{
Kaiwen Cui ${ }^{1}$, Aiping Zhang ${ }^{2}$ \\ ${ }^{1}$ Tarim University, Xinjiang, Alar, 843300
}

KEYWORDS: Floating Population; Security Prevention System; Sothern Xinjiang

\begin{abstract}
Floating population distribution and survival of the state is increasingly becoming the process of urbanization problems to be solved, it is not only concerned in Xinjiang leapfrog development prospects, but also a profound impact on security and stability and counterterrorism. This paper analyzes the population in urban adaptation constraints faced by various institutional and personal difficulties and restructuring management and service concepts, improve top-level design, launched a series of institutional support with equal treatment of citizens, contributed to the Urumqi migrants, orderly and effective integrated into urban society and built security and good harmony city.
\end{abstract}

\section{Introduction}

Migrants are accompanied by reform and opening up and socialist market economy and emerging social phenomenon and an inevitable trend, is a manifestation of social progress. According to incomplete statistics, since 1985, the floating population in our region at a rate of 20 million per year increase, in 2010 has reached 486 million, accounting for about one-fifth of the region's population. Among them, the mainland provinces to Xinjiang floating population accounted for $57 \%$; regional inter-regional mobility of the population accounted for 40 per cent of migrants; foreign and overseas migrants to Xinjiang accounts for 3.2\%. The region as a builder of floating population in Xinjiang, promote the development of economy and society in Xinjiang, but also inevitably to social management and public order has brought some negative impact, resulting in many new social problems. On the one hand, many of them migrants or no to enjoy some of the legal rights of citizens should have; on the other hand, some of them outside the effective management of human alienation, affects the social order and social stability of a large high-risk group. According to the Xinjiang public security organs to statistics, criminal cases in floating population accounts for about $40 \%$ of the total incidence of the above, public order cases accounting for more than $60 \%$ of the total incidence. In some places migrant populations, illegal migrants crime rate has reached $70 \%$. Visible, floating population crimes issue has become a prominent issue of social security is an important factor affecting social stability. Due to the dynamic nature, complexity, diversity, and a sharp increase in the number of floating population in Xinjiang, making migrants contradiction between maintaining stability and counter-terrorism issues more prominent. According to the Xinjiang public security organs to statistics, in recent years cracked the "three forces" violent terrorist gang members and more than $90 \%$ of cases are caught outside the domicile. In particular, the main suspect in 2008 in our region spate of "8 • 4", "8 • 10" cases and other violent terrorist activities have all in different places, different places development organizations, fled back to the local crime. We can say that most of these migrants are by no means 
hostile elements and the "three forces" molecules. For a long time, in some places due to the Urumqi floating population management and other factors become blind, chaotic situation and rental housing illegal construction has not been effectively checked, the basic situation of the floating population is unclear, area of social security in poor condition, brought many management problems.

\section{The Problems in Floating Population Community}

Social system is a society of fundamental social phenomenon, related to the social problems of social security, social security issues and social security problems run prevention. China's current 15 by the planned economy era legacy of the household registration system, dual system is one kind of urban-rural split, once in a particular historical period after the founding of promoting national economic development played an important role. In the early founding of China, we have to achieve rapid industrialization must take a planned economy dominated by the rural support urban, route information provided by the accumulated into agricultural industrialization.

Existing accounts and rely mainly on urban management unit, but the management of floating population and the lack of it is the unit of account, and therefore the current management of the floating population to rely on various types of documents to compensate, such as temporary residence permits, employment permits. But in fact, most residents are not ghettos migrants for temporary residence permits, employment permits, production and operation of businesses did not handle the relevant documents production and operation. As 30,000 migrant workers in Nanjing Xinglong street, there are about 35\% of "undocumented" people, Beijing "Zhejiang village" at the village, the proportion of 3742 employers no business license of up to 90 percent. These have led to local government and public security organs difficult for migrants targeted management, there are many loopholes in management. Public Security Organs bottom countless foreign population, the population will be foreign rental housing management to be inadequate, causing many rental housing are not included in the public security organs of management system, a dead city administration of public security. Many crime staff mobility is too strong, resulting in lower public security organs detection rate, he contributed to many criminals chances. The movement of people injured, in the case of failure of public relief, many will choose to "self-help" or resort to other "private relief", led to the creation of many retaliatory cases such evil forces have breeding space . In addition, the current preventive management mode simply put migrants regarded as the root causes of instability and the city's urban disease, a direct result of the floating population in urban society "marginalized." The current floating population prevention management style makes the floating population mainly because of passive low, rarely participate in management in the past; the floating population in order to fulfill obligations related, and few services available; the purpose of administration is negative, mainly to avoid security incidents based, with little regard to their own needs migrants.

A large number of floating population into the ground to tremendous pressure to live, not only is the center of the city, living space Floating Population Community has also been overload. In particular, many of the rural and peri-urban villages, the villagers in order to obtain greater benefits from rental housing, and to do everything possible alterations and new private homes for lease. Homestead unlawful appropriation within the neighborhood, building layout and space planning haphazard building density is too high, "handshake floor" can be seen everywhere within two meters, which gave the local environment is a big negative effect. This environment has become very easy to breed various criminal hotbeds are criminals hiding hiding the best place. 


\section{Floating Population Security Prevention and Control Countermeasures}

Innovation management, optimization services, management and service both according to "party and government-led sector to work together, community involvement, and make concerted efforts," the governance principles, firmly establish the "people-oriented" guiding ideology, under the unified leadership of party committees and governments, science Shi policy, and gradually improve the localization of the floating population service and management level, so that the concept of equal treatment, the same as accepting help, the same treatment on the dispute, as requirements management. Take various measures to provide employment for the population, medical care, social security and child education services, to respect and protect their legitimate rights and interests, improve their living and working environment, and guide them orderly flow, a fundamental solution to discrimination against migrants, exclusion not respected question.

To strengthen legislation, improve the social mobility of the population, protect the civil rights movement of people first, standardized management of floating population floating population management needs of national legislation to address migration flows, security management, family planning, children's education many problems employment medical care, security and other interests. However, this legislation should be combined with the household registration system, steadily. Secondly, from the point of view of Xinjiang, the importance of timely introduction of local regulations and implementing rules Xinjiang floating population service and management, so that foreign service personnel and management according to the law. Third, strengthen legislation on rental housing area. In 2003 the State Council abolished "rental housing registration approval" administrative examination and approval, the public security organs of the early management of rental housing lost grip, proactive management becomes post management, inevitably rental housing security management of the remaining passive. After the " 7 • 5 " events in Xinjiang by the pilot, we introduced the "Urumqi rental management regulations" to carry out a useful attempt in rental housing registration aspects of quasi-rents management.

Speed up institutional innovation, reduce the risk of institutionalization based on the theory of risk society, in order to avoid a variety of system and reduce the risk but will bring the risk of institutionalization. To reduce this risk of institutionalization, must be institutional innovation, the original system is unreasonable or part of the entire institutional system reform. Risk neighborhoods institutionalized migrants mainly from the continuation of years of the household registration system, unfair income distribution system and the absence of social security system, should increase efforts to reform the household registration system, the household registration management of floating population gradually integrated into society unified system of document management, the establishment and improvement of urban security system, breaking down barriers to the dual urban-rural migrants and urban residents between expanding the scope of social security, and constantly improve the medical insurance system, provide good health care to migrants health and epidemic prevention, family planning and other services.

Accelerate the establishment of floating population information system, give full play to its role in maintaining stability in the establishment of anti-terrorism floating population comprehensive information system is adapted to the current anti-terrorism stability maintenance situation, the need to reform and strengthen the Basic Public Security Work. Xinjiang is an effective way to improve the effectiveness of management of floating population. From a national perspective, relying on the existing provincial and municipal resident population of the repository, unified planning by the Ministry of Public Security, as soon as possible to establish a national Floating Population Information Network. In terms of provinces, set about establishing district, the county (city) set of three floating population service management information platform, not only to do basic outflow of 
population census data preservation and maintenance, but also good inflow of population-related information (job , live, life, etc.) collection and updates. Strengthening cooperation between the inflow and outflow, according to civil identification number, to establish a national system of exchange of information, and effectively implement the outflow associated with the inflow to the database, dynamically reflect the floating population of identity, reality show, change tracks, illegal crime information and so on.

\section{Conclusion}

Population Mobility of Xinjiang at this stage is not only a major economic issue of social transformation, but also a major political issue to maintain stability in Xinjiang. Floating population in our region has changed from the beginning of reform and opening to the main security problems involving social development, social development, comprehensive social management and social services, has not led the problem can be solved by a certain functional departments must Party mode and try by the light weight management services to management services, integrated services management among; under the unified leadership of the government's work in coordination, the progressive realization of the social security administration control-oriented model to a city overall planning, comprehensive management paradigm shift transformation; by the household population and transient population management track system to the community population management services real modal shift; dominated by the transition to management functions to improve the management of community-based service system of territorial management model; dominated by the government to government administration according to law, community law autonomy and grass-roots organizations to participate in a wide range of social services management transition.

\section{Acknowledgements}

Fund Project: Southern Xinjian, Social Governance Mechanism of Urban and Rural, National Social Science Fund Project, Project NO. 14AZD054.

\section{Reference:}

[1] Xie Yuan, Su Cheng. Xinjiang's population situation report [J] Xinjiang Social Science, 2008 (1): 124.

[2] Li Yong. Basic Public Security Work Si Xing Lu (2005-2006) [M]. Beijing: Chinese People's Public Security University Press, 2007: 227.

[3] National Population and Family Planning Commission floating population service management division floating population in China Development Report 2010 [R]. Beijing: China Population Publishing House, 2010 (General Report): 23.

[4] Zhao Jianmin, urban flow population right protection and crime prevention Discussion [J]. Chongqing Technology and Business University: West Forum, 2009 (1): 35. 